\title{
Envolvimento Religioso e Bem-Estar Subjetivo em Idosos
}

\author{
Religious Involvement and \\ Elderly Subjective Well-Being \\ Implicación Religiosa y Bienestar \\ Subjetivo en los Mayores
}
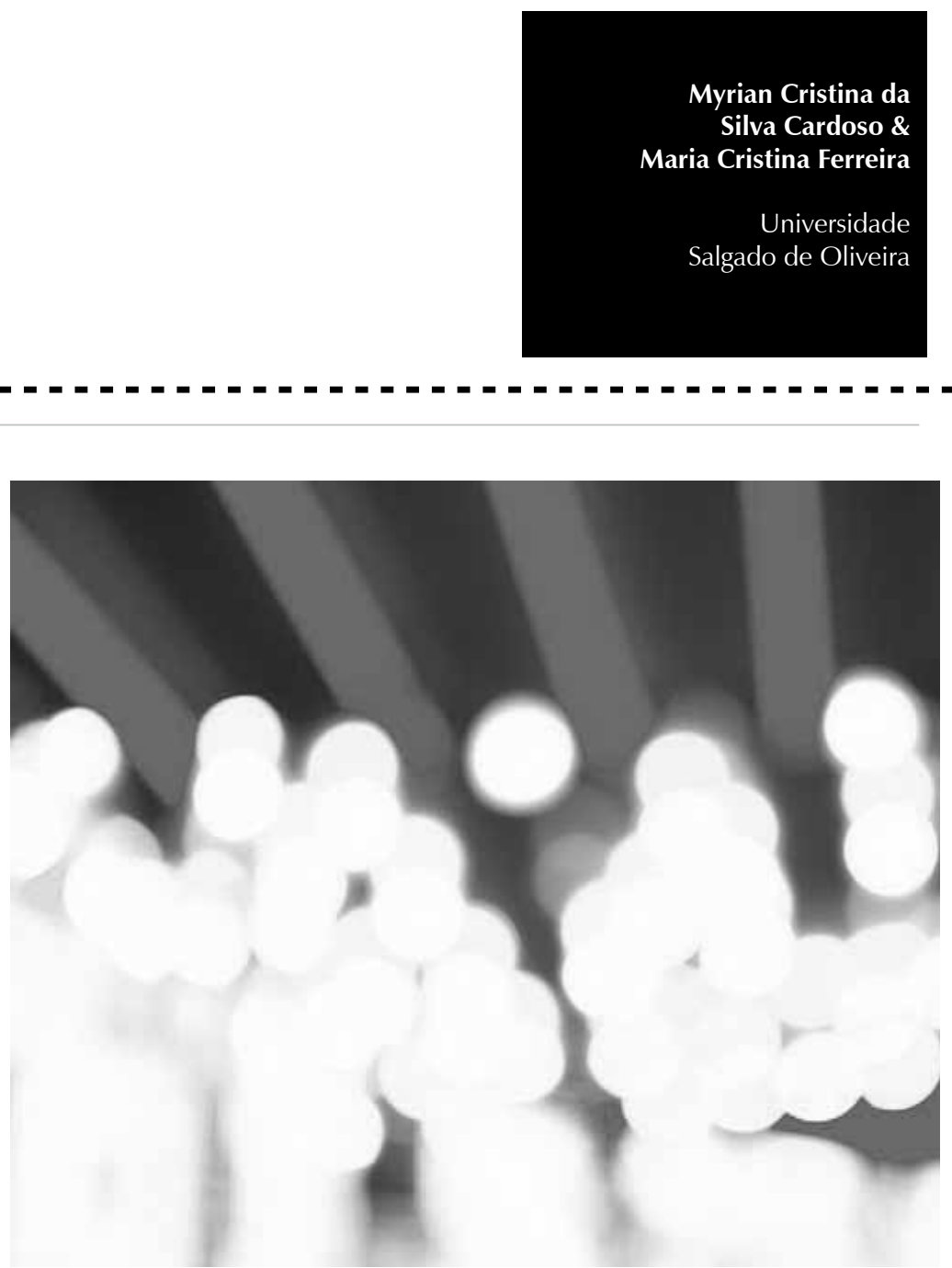
Resumo: As inter-relações do envolvimento religioso com o bem-estar subjetivo em idosos foram investigadas neste trabalho. Participaram da pesquisa 256 indivíduos de ambos os sexos, com idades variando de 60 a 90 anos, que responderam a três instrumentos destinados a mensurar sua satisfação com a vida, seus afetos positivos e negativos e seu envolvimento religioso bem como a perguntas de natureza sociodemográfica. Os resultados evidenciaram que, dentre as dimensões do envolvimento religioso, apenas a religiosidade subjetiva se correlacionou positiva e significativamente com a satisfação com a vida, que não foram observadas correlações entre o envolvimento religioso e os afetos positivos e negativos, e que os idosos protestantes apresentaram níveis mais elevados de afetos positivos que os católicos. Tais resultados são discutidos à luz dos estudos empíricos e dos modelos conceituais que deram suporte à pesquisa.

Palavras-chave: Bem-estar subjetivo. Envolvimento religioso. Terceira idade. Satisfação com a vida.

\begin{abstract}
The relationships between religious involvement and elderly subjective well-being were investigated in this paper. The participants were 256 elderly male and female, whose age ranged from 60 to 90 years old. They answered three instruments designed to measure life satisfaction, positive and negative affects and religious involvement, as well as questions related to social-demographic information. The results showed that in relation to the religious involvement dimensions, just the subjective religiosity had a positive and significant relationship with life satisfaction. Besides that there was no relationship between religious involvement and the positive and negative affects. The protestant elderly presented a higher level of positive affect than catholics did. The results are discussed based on empirical studies and conceptual models used as background for research.
\end{abstract}

Keywords: Subjective well-being. Religious involvement. Old age. Life satisfaction.

Resumen: Las interrelaciones del implicación religiosa con el bienestar subjetivo en los mayores fueron investigadas en este trabajo. Participaron de la pesquisa 256 individuos de ambos los sexos, con edades variando de 60 a 90 años, que contestaron a tres instrumentos destinados a medir su satisfacción con la vida, sus afectos positivos y negativos y su implicación religiosa así como la preguntas de naturaleza sociodemográfica. Los resultados evidenciaron que, entre las dimensiones de la implicación religiosa, apenas la religiosidad subjetiva se correlacionó positiva y significativamente con la satisfacción con la vida, que no fueron observadas correlaciones entre la implicación religiosa y los afectos positivos y negativos, y que los de edad protestantes presentaron niveles más elevados de afectos positivos que los católicos. Tales resultados son discutidos a la luz de los estudios empíricos y de los modelos de conceptos que dieron soporte a la pesquisa.

Palabras clave: Bienestar subjetivo. Implicación religiosa. Tercera edad. Satisfacción con la vida.

A longevidade e, em conseqüência, a população de idosos, vem crescendo consideravelmente nas últimas décadas em virtude do aumento da expectativa média de vida. Nos países em desenvolvimento, como o Brasil, por exemplo, o ritmo de envelhecimento é ainda mais rápido, e, por essa razão, acredita-se que essa população aumente quatro vezes mais nos próximos 50 anos. Desse modo, é provável que, ao chegar essa época, pela primeira vez na História, existam mais pessoas com idade superior a 60 anos do que crianças com menos de 15 anos, segundo estudos da Organização Mundial de Saúde (OMS, 2002).

Até recentemente, prevalecia na sociedade a visão de que a velhice consistia em algo negativo, associado à doença, à dependência e à falta de produtividade, isto é, às perdas biológicas, funcionais, psicológicas e sociais que a caracterizam. Tal concepção da velhice como um processo progressivo e irreversível de degeneração vem, no entanto, se modificando paulatinamente. Nesse sentido, a OMS (2002) defende a necessidade de se implementarem medidas capazes de promover o aproveitamento das competências e experiências adquiridas pelo idoso ao longo da vida, assim como a melhoria de seu ambiente físico (que deve ser favorável à manutenção de sua independência) e social, de modo a garantir a qualidade de vida na velhice.

Durante muito tempo, a qualidade de vida foi avaliada por meio de indicadores econômicos ou sociodemográficos (também denominados 
indicadores objetivos) que descreviam apenas as condições de vida dos indivíduos. Atualmente, porém, os indicadores sociais, que incluem critérios de julgamento pessoal do bem-estar e da satisfação com a vida, foram incorporados aos estudos sobre qualidade de vida.

Assim é que Pereira (1997), por exemplo, afirma que a avaliação da qualidade de vida implica não somente a consideração do bemestar objetivo, isto é, das condições de vida da pessoa, mas também do bem-estar subjetivo, ou seja, do modo pelo qual as pessoas percebem os diversos domínios de sua vida. De modo semelhante, Diener, Suh, Lucas e Smith (1999) enfatizam que a inclusão dos indicadores subjetivos é fundamental para a avaliação da qualidade de vida, já que os indicadores socioeconômicos descrevem apenas as condições de vida de uma pessoa por meio de variáveis demográficas e econômicas, não avaliando, portanto, o nível de satisfação em relação a essas condições.

De acordo com esses autores (Diener et al., 1999), a dimensão subjetiva da qualidade de vida, também chamada de bem-estar subjetivo, manifesta-se por meio da satisfação com a vida e de respostas emocionais. A satisfação com a vida associa-se à satisfação com domínios específicos da vida (lazer, saúde, finanças, vida pessoal/afetiva e grupo de pertença) e à satisfação global com a vida atual, passada e futura, assim como à visão dos outros significantes a respeito da própria vida. Já as respostas ou estados emocionais compreendem as emoções e estados de humor positivos ou agradáveis (alegria, orgulho, contentamento, amor próprio, carinho, felicidade e êxtase) e negativos ou desagradáveis (culpa e vergonha, tristeza, ansiedade e medo, raiva/irritação, estresse, depressão e inveja). Em outras palavras, para Diener (1994), o bem-estar subjetivo diz respeito aos motivos pelos quais as experiências pessoais se dão de forma positiva, razão pela qual se baseia tanto no julgamento cognitivo quanto nas reações afetivas resultantes dessas experiências.

Adotando posição similar, Lawton (1983), em seu modelo sobre qualidade de vida na velhice, considera que o bem-estar psicológico consiste na avaliação subjetiva da experiência interna do indivíduo quanto à sua vida em geral. Ainda segundo o autor, tal construto é multideterminado, sendo formado por quatro domínios ou indicadores: (1) satisfação com a vida, caracterizada como a avaliação cognitiva da vida em geral, levandose em conta o que o indivíduo tem e o que deseja ter, ou seja, seus objetivos e realizações pessoais, (2) felicidade, que consiste em um estado afetivo positivo e duradouro, (3) afetos positivos, considerados sentimentos transitórios de prazer relacionados muito mais à experiência emocional que ao julgamento racional e (4) afetos negativos, que também se caracterizam como sentimentos transitórios que expressam as emoções negativas de ansiedade, depressão, agitação, medo e pessimismo.

Numerosos estudos vêm sendo realizados nas últimas décadas com o intuito de descrever os diferentes fatores que interferem no bemestar subjetivo na velhice. Tais pesquisas têm demonstrado que o referido construto sofre a influência de múltiplos fatores de natureza física, sociodemográfica e social, como a saúde física (Lawton, Devoe, \& Parmelee, 1995; Sarvimaki \& Stenbock-Hult, 2000), a capacidade funcional (Moraes \& Souza, 2005; Paschoal, 2002), o gênero (Adkins, Martin, \& Poon, 1996; Koo, Rie, \& Park, 2004), a idade (Koo et al., 2004) e as relações familiares (Lawton et al., 1995; Moraes \& Souza, 2005).

Entre os determinantes sociais, merece destaque o envolvimento religioso, em virtude do papel que o mesmo desempenha na configuração dos níveis de bem-estar subjetivo dos idosos, razão pela qual diversas áreas, como a Medicina, a Psicologia e 
a Sociologia, vêm buscando elucidar as possíveis inter-relações existentes entre esses construtos.

O envolvimento religioso ou religiosidade compreende os comportamentos, atitudes, valores, crenças, sentimentos e experiências motivados pelo contexto religioso (Levin, Chatters, \& Taylor, 1995), desdobrandose em três dimensões: religiosidade organizacional, não-organizacional e subjetiva (Chatters, Levin, \& Taylor, 1992). A religiosidade organizacional compreende os comportamentos religiosos que ocorrem no contexto da instituição religiosa (como a freqüência às atividades religiosas formais) e o desempenho de cargos ou funções religiosas.

Já a religiosidade não-organizacional engloba os comportamentos religiosos privados ou informais, isto é, que ocorrem fora do contexto da instituição religiosa, sem local e tempo fixos e sem seguirem formas litúrgicas pré-estabelecidas, podendo se manifestar individualmente ou em pequenos grupos familiares e informais. São exemplos dessa dimensão a leitura da Bíblia e demais literaturas religiosas, os momentos de oração, o ouvir ou assistir programas religiosos, etc. A religiosidade subjetiva, por fim, associa-se aos aspectos psicológicos da religiosidade, ou seja, às crenças, conhecimentos e atitudes relativas à experiência religiosa bem como aos auto-relatos de tais experiências e ao significado pessoal atribuído à religião.

As possíveis associações existentes entre religião, qualidade de vida e bem-estar subjetivo vêm, há muito tempo, constituindose em objeto de preocupação dos estudiosos dessas áreas. Nesse sentido, Diener (1984), em sua célebre caracterização do bem-estar subjetivo, ressaltou que tanto as crenças quanto a participação nas atividades religiosas influenciam positivamente o bem-estar subjetivo das pessoas e, posteriormente, em revisão realizada em 1999, incluiu a religião entre as variáveis sociodemográficas que interferem nos níveis de bem-estar subjetivo.

Alinhadas com tais pressupostos, várias pesquisas têm evidenciado que o envolvimento religioso constitui-se em importante preditor da participação dos idosos em atividades sociais e comunitárias que lhes propiciam melhor funcionamento psicossocial (Wink \& Dillon, 2003; Young \& Dowling, 1987). Contudo, a participação dos idosos nas atividades religiosas formais costuma diminuir com a idade, em virtude dos problemas de saúde que comprometem sua atividade e funcionalidade física (Mindel \& Vaughan, 1978). Tal participação é, porém, compensada pela maior participação nas atividades religiosas não-formais e pelo aumento da devoção pessoal, que tendem a aumentar com a idade e contribuem sobremaneira para a manutenção dos níveis de bem-estar subjetivo dos idosos (Ellison, 1991). Adicionalmente, a religiosidade tem se mostrado também associada ao bem-estar psicológico, ou seja, aos aspectos que contribuem para o ajustamento na velhice, como, por exemplo, as relações positivas com os outros, a autoaceitação, o crescimento pessoal (Frazier, Mintz, \& Mobley) e a satisfação com a vida (Ellison, 1991; Hunsberger, 1985; Koenig, Kvale, \& Ferrel, 1988).

Em síntese, a religiosidade tem se destacado como uma variável capaz de contribuir para a promoção e a manutenção do bem-estar dos idosos, seja por meio do consolo espiritual, da rede de apoio social e/ou pelas regras de conduta moral e espiritual que ela estabelece. Ellison (1991), por exemplo, afirma que o envolvimento religioso proporciona aos idosos benefícios cognitivos, uma vez que ele influencia a forma como os indivíduos percebem suas experiências, aumentando assim seus sentimentos de auto-eficácia, de amor próprio, de controle e de segurança pessoal. Por outro lado, a experiência religiosa pode proporcionar, ainda, um senso de 
As pesquisas brasileiras

voltadas para

a análise de tal temática ainda são, porém, incipientes, e têm focado, isoladamente, ora alguns aspectos

relacionados à satisfação com a vida em idosos, ora aspectos associados à religiosidade em idosos

(Neri, 1995, 2000, 2001). significado para a vida, principalmente em momentos de crise, sendo tais benefícios ainda maiores quando os indivíduos não dispõem de outros recursos que possam contribuir para esse suporte, como é o caso das pessoas aposentadas e viúvas.

As pesquisas brasileiras voltadas para a análise de tal temática ainda são, porém, incipientes, e têm focado, isoladamente, ora alguns aspectos relacionados à satisfação com a vida em idosos, ora aspectos associados à religiosidade em idosos (Neri, 1995, 2000, 2001). Nesse sentido, não foram encontradas, na literatura consultada, referências a estudos destinados a abordar a relação entre essas duas variáveis. Fundamentando-se em tais considerações, o presente estudo teve como principal objetivo investigar as inter-relações do envolvimento religioso com o bemestar subjetivo em idosos. Adicionalmente, procurou também verificar, em amostras brasileiras de idosos, as características psicométricas das três diferentes escalas adotadas no estudo, quais sejam: Escala de Satisfação com a Vida, Escala de Afetos Positivos e Negativos e Escala de Envolvimento Religioso.

\section{Método}

\section{Participantes}

A amostra foi composta por 256 idosos de ambos os sexos (197 mulheres e 59 homens), com idades entre 60 e 87 anos (média de 69,12 e desvio-padrão de 6,42), pertencentes a diversas religiões $(43,8 \%$ eram católicos, $41,8 \%$ protestantes e os outros pertenciam a diversas outras religiões) e residentes em diversos bairros da cidade do Rio de Janeiro, que concordaram voluntariamente em participar da pesquisa. Desse total, $52 \%$ eram casados e $31,3 \%$ viúvos, sendo que, entre os casados, $37,6 \%$ eram homens e $62,4 \%$, mulheres, enquanto, entre os viúvos, $98,8 \%$ eram mulheres, o que demonstra a existência de uma fatia considerável de mulheres viúvas que se contrapõe aos homens de mesma idade que, em sua maioria, eram casados. Quanto ao nível de escolaridade, 56,3\% possuíam apenas o ensino fundamental, e $24,6 \%$, o ensino médio. Quando questionados sobre o fato de serem ou não membros oficiais da igreja ou instituição à qual pertenciam, $81,6 \%$ se consideraram membros oficiais. Já no que diz respeito ao desempenho de cargos ou funções na igreja ou instituição à qual pertenciam, 33,6\% responderam que não possuíam cargos ou funções.

Instrumentos

$\mathrm{Na}$ avaliação da satisfação com a vida, foi utilizado um questionário com 28 itens adaptados das Escalas de Lawton (1975) e de Neugarten, Havighurst e Tobin (1961). A Escala de Lawton, em sua versão original, compõe-se de 22 itens, distribuídos em 6 fatores (agitação, atitude em relação à própria idade, insatisfação com a solidão, aceitação do status quo, otimismo e desenvolvimento pessoal), enquanto a Escala de Neugarten et al. é composta de cinco fatores (prazer versus apatia, congruência entre desejos e realizações pessoais, resolução e fortaleza, autoconceito positivo e humor). Na montagem da escala para o presente estudo, foi feita uma seleção dos itens de ambas as escalas que se associavam à satisfação e à insatisfação com a vida. Tais itens foram respondidos em escalas tipo Likert de cinco pontos, variando de 1 (discordo totalmente) a 5 (concordo totalmente).

Para a mensuração dos afetos positivos e negativos, foi adotada a Escala PANAS, de autoria de Watson, Clark e Tellegen (1988), que se compõe de 20 itens, divididos igualmente entre os afetos positivos e negativos, a serem respondidos mediante 
escalas tipo Likert de cinco pontos, variando de 1 (discordo totalmente) a 5 (concordo totalmente).

Já para a avaliação do envolvimento religioso, foi utilizada a escala desenvolvida por Chatters et al. (1992), em sua versão original de 12 itens, distribuídos em três fatores: religiosidade organizacional, com cinco itens, religiosidade não-organizacional, com quatro itens, e religiosidade subjetiva, com três itens. Tais itens foram respondidos em escalas tipo Likert de cinco pontos, variando de 1 (nunca, nada importante ou nada religioso) a 5 (todo o dia, totalmente importante ou totalmente religioso).

Os itens das três escalas foram traduzidos e adaptados à realidade brasileira por um psicólogo bilíngüe, retraduzidos para o idioma inglês por outro psicólogo bilíngüe e, posteriormente, as duas versões foram avaliadas por uma terceira pessoa que resolveu as discrepâncias entre elas, mantendo a preocupação de dar maior destaque ao significado conotativo dos itens.

Em seguida, esses itens foram submetidos à validação semântica mediante a avaliação de três juízes, que os analisaram quanto à clareza e à compreensão. As modificações sugeridas foram então incorporadas às versões das escalas utilizadas durante a coleta de dados, e após todas elas foram submetidas à verificação de suas qualidades psicométricas, antes de serem utilizadas no Teste das Interrelações entre o Envolvimento Religioso e o Bem-estar Subjetivo. Os resultados referentes a tais análises são apresentados na primeira parte da seção de resultados.

\section{Procedimento}

Os participantes foram abordados em locais públicos onde se presumia a presença de idosos, tais como áreas de esportes/lazer e igrejas. No momento da abordagem, o entrevistador se apresentava, expunha os objetivos da pesquisa, indagava se o idoso atendia ao critério de ter um limite mínimo de 60 anos de idade e, em caso afirmativo, convidava-o a participar, enfatizando que o sigilo das respostas seria preservado. Caso aceitasse colaborar com a pesquisa, o participante era entrevistado individualmente. O tempo de preenchimento dos instrumentos variou de 10 a 20 minutos. Cumpre destacar, por fim, que os procedimentos de coleta de dados atenderam aos princípios éticos referentes à pesquisa com seres humanos e foram preliminarmente aprovados pelo Comitê de Ética em Pesquisa.

\section{Resultados}

Características psicométricas dos instrumentos de coleta de dados

Considerando-se a inexistência de estudos brasileiros de validação das Escalas de Satisfação com a Vida e de Envolvimento Religioso bem como da Escala PANAS em idosos, foi necessária a verificação preliminar das características psicométricas dessas escalas antes que elas fossem utilizadas na análise dos dados da pesquisa propriamente dita.

Para tanto, verificou-se inicialmente o atendimento aos pressupostos da análise fatorial de cada um dos instrumentos, mediante o cálculo da medida de adequação da amostra, de Kaiser-Meyer-Olkin (KMO), e do Teste de Esfericidade, de Bartlett. Em seguida, a matriz de intercorrelações entre os itens de cada um dos três instrumentos foi inicialmente submetida à análise dos componentes principais e à inspeção do teste gráfico (scree plot), o que possibilitou a verificação do número máximo de fatores interpretáveis em cada caso. Posteriormente, foram realizadas, nos dados de cada instrumento, análises fatoriais dos eixos principais, com a determinação antecipada do 
número de fatores, por meio do método de rotação oblíqua (oblimim), em virtude da expectativa de que os fatores pudessem se apresentar correlacionados. Logo após, foi examinada a solução que melhor representou a estrutura interna da escala, e nela foram retidos os itens que apresentaram cargas fatoriais iguais ou superiores a 0,30 e consistência semântica com os demais itens do fator. Por fim, a consistência interna de cada fator retido foi verificada, mediante o cálculo do coeficiente Alpha de Cronbach.

Tabela 1. Comunalidades e cargas fatoriais dos itens que compuseram a escala de satisfação com a vida.

Itens

Comunalidades

Cargas fatoriais

1- As coisas vão se tornando piores à medida que envelheço

0,40

$-0,48$

2- Sinto-me muito sozinho (a)

0,27

0,47

6- Às vezes sinto que a vida não vale a pena

0,19

$-0,41$

8- Sinto-me tão feliz hoje como quando eu era mais jovem

0,28

0,46

9- Tenho muitas coisas sobre as quais me entristecer

0,34

$-0,49$

10- À medida que avalio a minha vida, sinto-me totalmente satisfeito (a)

0,32

0,51

14- Este é o período mais triste da minha vida

0,31

$-0,46$

15- Minha vida poderia ser mais feliz do que ela é atualmente

0,34

$-0,52$

16- Estes são os melhores anos da minha vida

0,30

0,50

26- Quando penso sobre minha vida passada, percebo que

não consegui muitas das coisas importantes que gostaria de obter

0,23

$-0,38$

27- Tenho obtido mais do que esperava obter

0,19

0,31

28- À medida que envelheço, as coisas ficam

melhores do que imaginei que seriam

0,34

0,49

Na escala de satisfação com a vida, o KMO foi igual a 0,84 , e o Teste de Bartlett, significativo $\left(\chi^{2}\right.$ $=1079,97 ; p<0,001)$, numa demonstração da pertinência de se realizar a análise fatorial. A análise dos componentes principais extraiu nove fatores com eingenvalues acima de 1 , responsáveis por $54,0 \%$ da variância total do instrumento. O teste gráfico revelou, porém, um número de um a quatro fatores interpretáveis. Nesse sentido, foram realizadas, em seguida, análises fatoriais dos eixos principais com soluções antecipadas de 1, 2, 3 e 4 fatores, tendo-se verificado que a solução de um fator foi a que forneceu a melhor representação da estrutura interna da escala. Esse fator explicou 12,3\% da variância total do instrumento, obteve eingenvalue igual a 3,43 e ficou com 12 itens associados a estados de humor (solidão, tristeza ou felicidade) e a atitudes de satisfação ou insatisfação com a própria vida na velhice (Tabela 1). O coeficiente Alfa de Cronbach desse fator foi igual a 0,76. A escala é corrigida no sentido da satisfação, e, assim, quanto maior o escore, maior a satisfação com a própria vida. 
Tabela 2. Comunalidades e cargas fatoriais dos itens que compuseram a Escala de Afetos Positivos e Negativos (PANAS).

\begin{tabular}{lll}
\hline Subescala de afetos negativos & Comunalidades & Cargas fatoriais \\
\hline 2- Sinto-me irritado (a) & 0,38 & 0,59 \\
3- Sinto-me angustiado (a) & 0,25 & 0,45 \\
7- Sinto-me transtornado (a) & 0,30 & 0,50 \\
10- Sinto-me nervoso (a) & 0,50 & 0,69 \\
11- Sinto-me culpado (a) & 0,19 & 0,34 \\
13- Sinto-me assustado (a) & 0,42 & 0,58 \\
15- Sinto-me hostil & 0,20 & 0,43 \\
16- Sinto-me tenso (a) & 0,40 & 0,61 \\
20- Sinto-me amedrontado (a) & 0,40 & 0,57 \\
Subescala de afetos positivos & Comunalidades & Cargas fatoriais \\
\hline 1- Sinto-me interessado (a) & 0,18 & 0,36 \\
5- Sinto-me animado (a) & 0,43 & 0,63 \\
8- Sinto-me inspirado (a) & 0,23 & 0,44 \\
9- Sinto-me seguro (a) & 0,27 & 0,42 \\
12- Sinto-me determinado (a) & 0,19 & 0,43 \\
17- Sinto-me entusiasmado (a) & 0,42 & 0,68 \\
18- Sinto-me dinâmico (a) & 0,30 & 0,52 \\
\hline
\end{tabular}

Na Escala de Afetos Positivos e Negativos (PANAS), obteve-se um índice KMO de 0,86, tendo o Teste de Bartlett se mostrado significativo $\left(\chi^{2}=1017,94 ; p<0,001\right)$, evidenciando, assim, ser possível a realização da análise fatorial. Na análise dos componentes principais, foram extraídos três fatores com eingeinvalues maiores que 1, responsáveis por $24,74 \%$ da variância total do instrumento. O teste gráfico revelou, porém, um número de dois a três fatores interpretáveis. Considerando-se, porém, que a escala original era composta de dois fatores e que tal solução era a mais apropriada do ponto de vista conceitual, foi realizada, em seguida, uma análise fatorial dos eixos principais com solução antecipada de dois fatores, que forneceu uma boa representação da estrutura interna da escala. O fator 1 apresentou eingenvalue igual a 3,24, e foi responsável por $16,2 \%$ da variância total do instrumento, tendo sido composto por nove itens que representam os afetos negativos. Já o fator 2 ficou com sete itens que definem os afetos positivos, tendo apresentado eingeinvalue igual a 1,71 e sido responsável por $8,5 \%$ da variância total do instrumento (Tabela 2). Os coeficientes Alpha de Cronbach desses fatores revelaram resultados iguais a 0,79 e 0,70, respectivamente. Tais fatores são corrigidos no sentido da característica mensurada, e, assim, quanto maior o resultado, maior o grau daquela característica. 
Tabela 3. Comunalidades e cargas fatoriais dos itens que compuseram a Escala de Envolvimento Religioso.

Subescala de participação religiosa

1- Participo de missas, cultos e reuniões na igreja

ou organização religiosa a que pertenço

2- Participo de outras atividades realizadas na

igreja ou organização religiosa a que pertenço

3- Leio a Bíblia, livros ou outros materiais religiosos

4- Assisto ou ouço programas religiosos de tv ou rádio

6- Costumo pedir aos outros que orem ou rezem por mim

Subescala de religiosidade subjetiva

8- Qual o valor da oração para sua vida?

9- Quão importante foi para você a religião durante

o seu crescimento?

10- Quão importante é o fato de os pais levarem

ou incentivarem seus filhos a freqüentarem a igreja?

\section{Comunalidades Cargas fatoriais}

$0,53 \quad 0,78$

$0,50 \quad 0,72$

$0,33 \quad 0,64$

$0,21 \quad 0,46$

0,50

Comunalidades Cargas fatoriais

$0,49 \quad 0,54$

$0,22 \quad 0,55$

$0,48 \quad 0,71$

Na Escala de Envolvimento Religioso, o KMO foi de 0,88, e o Teste de Bartlett também se mostrou significativo, apontando, desse modo, a adequação dos dados à realização da análise fatorial. A análise dos componentes principais extraiu três fatores com eingeinvalues superiores a 1, responsáveis por 34,8\% da variância total do instrumento, o que foi confirmado pelo teste gráfico, ao demonstrar a existência de um número entre dois a três fatores interpretáveis. Em conseqüência, foram realizadas, posteriormente, análises fatoriais dos eixos principais com dois e três fatores. A solução que representou a melhor estrutura interna da escala foi a de dois fatores. $\mathrm{O}$ fator 1 ficou composto por 5 itens, e apresentou eingeinvalue igual a 3,00, tendo sido responsável por $27,3 \%$ da variância total. Seus itens associam-se às atividades religiosas formais e informais, e, por essa razão, ele foi denominado participação religiosa. Já o fator 2 apresentou eingeinvalue igual a 1,00, e foi responsável por 7,5\% da variância total do instrumento. Os três itens que o compuseram associaram-se à importância que o indivíduo atribui à religião e, por isso, ele foi intitulado de religiosidade subjetiva (Tabela 3). Os coeficientes Alfa de Cronbach desses fatores foram iguais a 0,73 e 0,69, respectivamente. Tais fatores são também corrigidos no sentido da característica mensurada e, assim, quanto maior o resultado, maior o grau daquela característica.

Os resultados obtidos evidenciaram, portanto, que todas as três escalas apresentaram características psicométricas adequadas no que tange à sua validade fatorial e precisão, numa demonstração de que as mesmas poderiam ser utilizadas na análise dos dados das etapas subseqüentes da pesquisa.

Análise dos dados da pesquisa

Para a análise dos dados da pesquisa, os indivíduos receberam inicialmente um escore em cada uma das dimensões do bem-estar subjetivo (satisfação com a vida, afetos positivos e afetos negativos) e do envolvimento religioso (participação religiosa e religiosidade subjetiva), mediante o cálculo das médias dos escores atribuídos aos itens que compunham essas diferentes subescalas. Em seguida, foram computadas as médias e os desvios-padrão de todas as subescalas bem como as correlações de Pearson entre elas. 
Tais resultados evidenciaram que a participação religiosa e a religiosidade subjetiva apresentaram correlações positivas e significativas com a satisfação com a vida $\left(r_{x y}=0,20 ; p<0,01\right.$ e $r_{x y}=0,27$; $p<0,01$, respectivamente). Por outro lado, os afetos positivos e negativos não apresentaram correlações significativas com tais dimensões do envolvimento religioso.

Em seguida, para se verificar as relações do envolvimento religioso com o bem-estar subjetivo, foram realizadas análises de regressão múltipla linear hierárquica, destinadas a verificar o poder preditivo das duas dimensões da escala de envolvimento religioso em cada uma das três dimensões do bem-estar subjetivo. Tais análises se efetivaram mediante o teste de dois diferentes modelos: o primeiro incluiu as variáveis idade, estado civil, escolaridade, gênero, religião, filiação religiosa oficial e exercício de cargo religioso, enquanto o segundo modelo incorporou à equação as duas subdimensões do envolvimento religioso, a saber: participação religiosa e religiosidade subjetiva.

Tabela 4. Regressão múltipla linear das variáveis sociodemográficas e do envolvimento religioso na satisfação com a vida.

\begin{tabular}{|c|c|c|c|c|}
\hline Variáveis & $\triangle \mathrm{R} 2$ & $\beta$ & $\mathrm{t}$ & $\mathrm{p}$ \\
\hline Modelo 1 & 0,05 & & & \\
\hline Idade & & 0,02 & 0,38 & 0,701 \\
\hline Estado civil & & $-0,10$ & $-1,47$ & 0,143 \\
\hline Escolaridade & & $-0,03$ & $-0,40$ & 0,693 \\
\hline Gênero & & $-0,06$ & $-0,95$ & 0,344 \\
\hline Religião & & 0,04 & 0,54 & 0,589 \\
\hline Filiação religiosa & & 0,04 & 0,54 & 0,589 \\
\hline Cargo religioso & & $-0,12$ & $-1,72$ & 0,087 \\
\hline Modelo 2 & 0,06 & & & \\
\hline Idade & & 0,08 & 1,20 & 0,232 \\
\hline Estado civil & & $-0,07$ & $-1,18$ & 0,241 \\
\hline Escolaridade & & $-0,06$ & $-1,00$ & 0,316 \\
\hline Gênero & & $-0,08$ & $-1,30$ & 0,193 \\
\hline Religião & & 0,01 & $-0,14$ & 0,892 \\
\hline Filiação religiosa & & $-0,07$ & $-1,00$ & 0,318 \\
\hline Cargo religioso & & $-0,04$ & $-0,61$ & 0,541 \\
\hline Participação religiosa & & 0,07 & 0,89 & 0,374 \\
\hline Religiosidade subjetiva & & 0,25 & 3,75 & 0,000 \\
\hline
\end{tabular}

A análise de regressão múltipla linear hierárquica, tendo como variável dependente a satisfação com a vida (Tabela 4), revelou que o primeiro modelo explicou apenas $5 \%$ da variância ( $F[7$, $248]=2,02 ; p>0,05)$, e, desse modo, o bloco de variáveis nele contido não contribuiu de forma significativa para a predição da satisfação com a vida. A entrada das duas subdimensões do envolvimento religioso, no segundo modelo, resultou em um acréscimo significativo de $6 \%$ $(F[2,246]=8,64 ; p<0,001)$ na explicação da satisfação com a vida, sendo que, dentre as variáveis preditoras, apenas a religiosidade subjetiva se correlacionou significativa e positivamente com a satisfação com a vida ( $\beta=0,25, t=3,75, p<0,001)$, numa evidência de que, entre as dimensões do envolvimento religioso investigadas, a religiosidade subjetiva foi a única capaz de predizer a satisfação com a vida. 
Tabela 5. Regressão múltipla linear das variáveis sociodemográficas e do envolvimento religioso nos afetos positivos.

\begin{tabular}{|c|c|c|c|c|}
\hline Modelo 1 & $\begin{array}{l}\triangle R 2 \\
0,05\end{array}$ & $\beta$ & $\mathrm{t}$ & $\mathrm{p}$ \\
\hline Idade & & $-0,05$ & $-0,81$ & 0,419 \\
\hline Estado civil & & 0,45 & 0,69 & 0,492 \\
\hline Escolaridade & & 0,02 & 0,37 & 0,714 \\
\hline Gênero & & 0,03 & $-0,40$ & 0,690 \\
\hline Religião & & 0,20 & 3,07 & 0,002 \\
\hline Filiação religiosa & & $-0,01$ & $-0,09$ & 0,931 \\
\hline Cargo religioso & & $-0,02$ & $-0,30$ & 0,768 \\
\hline Modelo 2 & 0,00 & & & \\
\hline Idade & & $-0,05$ & $-0,74$ & 0,459 \\
\hline Estado civil & & 0,04 & 0,64 & 0,520 \\
\hline Escolaridade & & 0,03 & 0,41 & 0,685 \\
\hline Gênero & & $-0,02$ & $-0,36$ & 0,717 \\
\hline Religião & & 0,21 & 3,08 & 0,002 \\
\hline Filiação religiosa & & $-0,02$ & $-0,22$ & 0,824 \\
\hline Cargo religioso & & $-0,04$ & $-0,48$ & 0,629 \\
\hline Participação religiosa & & $-0,05$ & $-0,64$ & 0,523 \\
\hline Religiosidade subjetiva & & 0,22 & 0,32 & 0,752 \\
\hline
\end{tabular}

Utilizando como variável dependente os afetos positivos, a análise de regressão múltipla linear hierárquica (Tabela 5) indicou que o primeiro modelo explicou apenas $5 \%$ da variância $(F[7,248]$ $=1,77 ; p>0,05)$ e não foi significativo, o mesmo ocorrendo com o segundo modelo, que em nada contribuiu para a explicação da variância dos afetos positivos $(F[2,246]=0,22 ; p>0,05)$. Sendo assim, não foram encontradas correlações significativas entre as dimensões do envolvimento religioso (participação religiosa e religiosidade subjetiva) e os afetos positivos.

Considerando-se, entretanto, o fato de, nessa análise de regressão, a religião ter apresentado um coeficiente $\beta$ significativo, as possíveis relações entre essa variável e os afetos positivos foram examinadas mais detidamente. Contudo, a maioria da amostra se classificou como católica $(43,8 \%)$ ou protestante $(41,8 \%)$, com apenas uma pequena parcela se classificando como espírita $(12,1 \%)$ ou pertencendo a outras religiões (2,3\%). Desse modo, foram comparados os níveis de afetos positivos obtidos apenas nos dois primeiros grupos, mediante o cálculo do Teste t para amostras independentes. Os resultados apontaram uma diferença significativa entre católicos e protestantes $(t=3,13 ; p<0,01)$, com os protestantes apresentando uma média $(4,50)$ significativamente superior aos católicos $(4,20)$, numa indicação de que os primeiros obtiveram um índice de afetos positivos significativamente maior que os segundos. 
Tabela 6 . Regressão múltipla linear das variáveis sociodemográficas e do envolvimento religioso nos afetos negativos.

\begin{tabular}{|c|c|c|c|c|}
\hline Modelo 1 & $\begin{array}{l}\triangle R 2 \\
0,03\end{array}$ & $\beta$ & $\mathrm{t}$ & $p$ \\
\hline Idade & & $-0,05$ & $-0,77$ & 0,440 \\
\hline Estado civil & & 0,00 & 0,04 & 0,972 \\
\hline Escolaridade & & $-0,00$ & $-0,05$ & 0,958 \\
\hline Gênero & & 0,05 & 0,68 & 0,495 \\
\hline Religião & & $-0,08$ & 3,07 & 0,002 \\
\hline Filiação religiosa & & $-0,06$ & $-0,94$ & 0,346 \\
\hline Cargo religioso & & 0,14 & 2,12 & 0,035 \\
\hline Modelo 2 & 0,00 & & & \\
\hline Idade & & $-0,06$ & $-0,98$ & 0,329 \\
\hline Estado civil & & $-0,00$ & $-0,07$ & 0,947 \\
\hline Escolaridade & & 0,01 & 0,13 & 0,899 \\
\hline Gênero & & $-0,05$ & 0,78 & 0,438 \\
\hline Religião & & $-0,07$ & $-0,97$ & 0,333 \\
\hline Filiação religiosa & & $-0,08$ & $-1,08$ & 0,279 \\
\hline Cargo religioso & & 0,12 & 1,61 & 0,110 \\
\hline Participação religiosa & & $-0,03$ & $-0,37$ & 0,713 \\
\hline Religiosidade subjetiva & & $-0,07$ & $-1,01$ & 0,316 \\
\hline
\end{tabular}

Na predição dos afetos negativos (Tabela 6), a análise de regressão múltipla linear demonstrou que o primeiro bloco de variáveis foi responsável por apenas $3 \%$ de sua variância $(F[7,248]=$ $1,10 ; p>0,05)$, e não foi significativo. $\mathrm{O}$ acréscimo das dimensões do envolvimento religioso (participação religiosa e religiosidade subjetiva), no segundo modelo, também não contribuiu significativamente para a explicação dos afetos negativos $(F[2,246]=0,69 ; p>0,05)$. Tais resultados evidenciaram, portanto, que não foram encontradas correlações significativas entre as dimensões do envolvimento religioso e os afetos negativos.

\section{Discussão}

Foi objetivo da presente pesquisa identificar as dimensões do envolvimento religioso que atuariam como preditoras das dimensões do bem-estar subjetivo. A análise dos dados evidenciou que a religiosidade subjetiva contribuiu de forma significativa para a predição da satisfação com a vida, numa indicação de que, quanto maior a religiosidade subjetiva, maior a satisfação com a vida. Tais resultados assemelham-se aos encontrados por outros autores (Hunsberger, 1985; Koenig et al., 1988) que também obtiveram correlações positivas e significativas entre a religiosidade subjetiva e a satisfação com a vida em idosos.

Uma possível explicação para os resultados ora obtidos reside no fato de que a religiosidade subjetiva, segundo Ellison (1991), produz um padrão de interpretação para os eventos e experiências da vida capaz de amenizar seus efeitos negativos, proporcionando benefícios espirituais (consolo e orientação) e psicológicos (um senso de controle pessoal diante das situações problemáticas da vida). Segundo o autor, então, a religiosidade subjetiva atuaria tanto em nível cognitivo quanto afetivo, ou seja, influenciaria a percepção de mundo do indivíduo, levando-o, assim, a experimentar maiores níveis de satisfação com a vida e de afetos positivos e negativos. 
$\mathrm{Na}$ atual investigação, porém, a religiosidade subjetiva associou-se apenas à satisfação com a vida, o que pode se dever ao fato de que os afetos costumam ser mais instáveis e vulneráveis à influência de eventos transitórios (Myers \& Diener, 1995). Desse modo, a identificação dos efeitos da religiosidade sobre os mesmos poderia ser dificultada por essas contingências eventuais, diferentemente da satisfação com a vida que, em virtude de se constituir em um componente mais cognitivo, seria, por conseguinte, mais estável e menos vulnerável às mudanças do dia a dia.

Foi observado, também, que os idosos protestantes obtiveram índices significativamente mais altos de afetos positivos, quando comparados aos idosos católicos. Tal diferença pode se dever ao fato de os primeiros darem maior ênfase aos aspectos doutrinários e à devoção pessoal, e, em conseqüência, apresentarem maior adesão às crenças religiosas. Talvez por essa razão, esses indivíduos apresentam melhores condições de lidar com as situações traumáticas da vida e com seus efeitos potencialmente negativos, como, por exemplo, os sentimentos negativos decorrentes de tais situações (Ellison, 1991). Em outras palavras, sua maior adesão às crenças religiosas seria a responsável por fazê-los lidar de forma mais positiva com as situações negativas do dia a dia, e, assim, eles apresentariam maiores índices de afetos positivos, em comparação com os católicos, que não costumam apresentar o mesmo grau de adesão às crenças de sua religião.
Em síntese, os dados ora obtidos apontam a importância do suporte espiritual, emocional e social fornecido pela religião para o bem-estar na velhice. No entanto, tornam-se necessárias novas investigações capazes de estender e aprofundar os resultados presentemente obtidos, especialmente no que tange aos mecanismos psicológicos e sociais que se encontram subjacentes ao bem-estar dos idosos. Nesse sentido, seria interessante, por exemplo, a realização de pesquisas voltadas para a análise das inter-relações entre o bemestar subjetivo e a religiosidade, em outros grupos religiosos, em faixas etárias mais amplas e em idosos com perfis distintos (ativos, sedentários, asilados, não asilados, etc.).

À guisa de conclusão, cumpre registrar que a pesquisa em foco teve caráter eminentemente exploratório, na medida em que não foram encontrados estudos brasileiros sobre tal temática na literatura consultada. De todo modo, foi possível trazer à discussão importantes questões inerentes aos fatores que contribuem para o envelhecimento bemsucedido bem como ressaltar a importância dos aspectos religiosos que indubitavelmente participam desse processo, mas que ainda são pouco abordados em nossos meios acadêmicos. Seria desejável, portanto, que tal linha de investigação prosseguisse em direção ao aprofundamento da referida temática, visto que a realização de tais estudos certamente irá se reverter em ganhos reais para os profissionais e instituições que atuam junto à população de idosos. 
Myrian Cristina da Silva Cardoso

Mestre em Psicologia

E-mail: mcris_4@yahoo.com.br

Maria Cristina Ferreira*

Doutora em Psicologia. Professora titular da Universidade Salgado de Oliveira

*Endereço para envio de correspondência:

Rua Marquês de Valença, 80, ap. 602, Rio de Janeiro - RJ - Brasil, CEP: 20550 - 030

E-mail: mcris@centroin.com.br

Recebido 04/05/2008 Reformulado 22/11/2008 Aprovado 13/12/2008

\section{Referências}

Adkins, G., Martin, P., \& Poon, L. W. (1996). Personality traits and states as predictors of subjective well-being in centenarians, octogenarians and sexagenarians. Psychology and Aging, 12, 408-416.

Chatters, L. M., Levin, J. S., \& Taylor, R. J. (1992). Antecedents and dimensions of religious involvement among older black adults. Journal of Gerontology, 47, 269-278.

Diener, E. (1984). Subjective well-being. Psychological Bulletin, $95,542-575$

Diener, E. (1994). Assessing subjective well-being: Progress and opportunities. Social Indicators Research, 31, 103-157.

Diener, E., Suh, E. M., Lucas, R. E., \& Smith, H. L. (1999). Subjective well- being: Three decades of progress. Psychological Bulletin, 125, 276- 302.

Ellison, C. G. (1991). Religious involvement and subjective well-being. Journal of Health and Social Behavior, 32, 80-99.

Frazier, C., Mintz, L. B., \& Mobley, M. (2005). A multidimensional look at religious involvement and psychological well-being among urban elderly African Americans. Journal of Counseling Psychology, 52, 583-590.

Hunsberger, B. (1985). Religion, age, life satisfaction and perceived sources of religiousness: A study of older persons. Journal of Gerontology, 40, 615-620.

Koenig, H. G., Kvale, J. N., \& Ferrel, C. (1988). Religion and well-being in later life. The Gerontologist, 28, 18-28.

Koo, J., Rie, J., \& Park, K. (2004). Age and gender differences in affect and subjective well-being. Geriatrics and Gerontology International, 4, 268-270.

Lawton, M. P. (1975). The Philadelphia Geriatric Center morale scale: A revision. Journal of Gerontology, 30, 85-89.

Lawton, M. P (1983). Environment and other determinants of well-being in older people. The Gerontologist, 23, 349-357.

Lawton, M. P., Devoe, M. R., \& Parmelee, P. (1995). Relationship of events and affect in the daily life of an elderly population. Psychology and Aging, 10, 469-477.

Levin, J. S., Chatters, L. M., \& Taylor, R. J. (1995). A multidimensional measure of religious involvement for African Americans. The Sociological Quarterly, 36, 157-173.

Mindell, C. H., \& Vaughan, C. E. (1978). A multidimensional approach to religiosity and disengagement. Journal of Gerontology, 33, 103-108.
Moraes, J. F. D., \& Souza, V. B. A. (2005). Fatores associados ao envelhecimento bem-sucedido de idosos socialmente ativos da região metropolitana de Porto Alegre. Revista Brasileira de Psiquiatria, 27, 302-308.

Myers, D., \& Diener, E. (1995). Who is happy? Psychological Science, 6, 10-19.

Neri, A. L. (1995). Psicologia do envelhecimento: temas selecionados na perspectiva de curso de vida. São Paulo: Papirus.

Neri, A. L. (2000). Qualidade de vida e idade madura. São Paulo: Papirus.

Neri, A. L. (2001). Maturidade e velhice: trajetórias individuais e socioculturais. São Paulo: Papirus.

Neugarten, B. L., Havighurst, R. J., \& Tobin, S. S. (1961). The measurement of life satisfaction. Journal of Gerontology, $16,134-143$.

Organização Mundial de Saúde. (2002). 2a Assembléia Mundial sobre o Envelhecimento - ONU. Recuperado em 15 de março de 2005, de http://www.onuportugal.pt/body_intro.html

Paschoal, S. M. P. (2002). Autonomia e independência. In M. P Netto \& J. R. Ponte (Orgs.), Gerontologia: a velhice e o envelhecimento em visão globalizada (pp. 313-323). São Paulo: Atheneu

Pereira, C. A. A. (1997). Um panorama histórico-conceitual acerca das subdimensões de qualidade de vida e bem-estar subjetivo. Arquivos Brasileiros de Psicologia, 49, 32-48.

Sarvimaki, A., \& Stenbock-Hult, B. (2000). Quality of life in old age described as a sense of well-being, meaning and value. Journal of Advanced Nursing, 32, 1025-1033.

Watson, D., Clark, L. A., \& Tellegen, A. (1988). Development and validation of brief measures of positive and negative affect: The PANAS scales. Journal of Personality and Social Psychology, 54, 1063-1070.

Wink, P., \& Dillon, M. (2003). Religiousness, spirituality and psychosocial functioning in late adulthood: Findings from a longitudinal study. Psychology and Aging, 18, 916-924.

Young, G., \& Dowling, W. (1987). Dimensions of religiosity in old age: Accounting for variation in types of participation. Journal of Gerontology, 41, 376-380. 